\title{
Environmental Quality in Economic Development in Low-Income Countries: Application of an EQT Model using Cross-Country Sample Data
}

\author{
Fidel Ezeala-Harrison ${ }^{1}$ \\ ${ }^{1}$ Department of Economics and Finance, Jackson State University, Jackson, USA \\ Correspondence: Fidel Ezeala-Harrison, Department of Economics and Finance, Jackson State University, PO \\ Box 17760, Jackson, MS 39217, USA. Tel: 1-601-979-2604. E-mail: fidel.ezeala-harrison@jsums.edu
}

Received: December 31, 2014 Accepted: January 21, 2015 Online Published: March 30, 2015

doi:10.5539/jsd.v8n2p122 URL: http://dx.doi.org/10.5539/jsd.v8n2p122

\begin{abstract}
Past studies have tended to inquire as to whether there is evidence that economic growth negatively impacts environmental quality. This remains and has always been an ample question to ponder with regard to the case of high-income countries. In terms of the low-income countries, however, the reverse question seems to be more appropriate given that the main concern in these countries is relatively more about growth than the environment. This paper develops an Environmental Quality Trajectory (EQT) model and applies it to provide a theoretical and empirical analysis of the importance of environmental quality, and how it impacts economic growth and development for developing countries. The study reveals some very important issues concerning the environment and the major factors that shape its role in economic growth and development in low-income countries. And most importantly, the study's results appear to generally lend support to aspects of the Ruttan-Kuznets propositions about the relationship between income and environmental quality in developing countries, and at the same time seem to refute some aspects of it, to the effect that the implications of the environmental Kuznets curve does not seem to hold equally to all low-income countries per se, as ordinarily believed hitherto.
\end{abstract}

Keywords: environmental quality, environmental degradation, pollution haven, kuznets curve, economic growth, depletion stress

\section{Introduction}

This paper presents an Environmental Quality Trajectory (EQT) model that is applied to determine effective ways of implementing some growth-enhancing environmental quality management for low-income countries. Past studies have tended to inquire as to whether or not there is evidence that economic growth negatively impacts environmental quality (Alpay, 2001; Grossman \& Krueger, 1994). This remains and has always been an ample question to ponder with regard to the case of high-income countries. In terms of the low-income countries, however, the reverse question seems to be more appropriate given that the main concern in these countries is relatively more about growth than the environment. More specifically, it has become a well recognized notion among economists and policy makers that a nation's environmental situation does have some significant bearing on its state of economic growth and development. And for developing countries, the environmental degradation problem is compounded by their being generally perceived and used as pollution havens (Levinson \& Taylor, 2013).

Environmental degradation retards economic growth in low-income countries, both in the short run and long run; but poor countries seem to believe that they need to achieve high levels of economic growth in order to address their rising poverty levels. Thus, many developing countries appear to have adopted an environmental attitude of "grow the economy first, and then clean up any environmental shortfall later". Therefore, as pollution havens, the pace of environmental degradation in the developing countries tends to be far ahead of the situation in the rich developed countries. And because of the immense negative impacts that environmental degradation portends for potential economic growth and development in poor countries, the present EQT model is hereby proposed to evaluate the lax environmental quality attitudes in poor countries, and to explore policy options for alternative approaches for reduction of the massive levels of environmental degradation that tend to retard the pace of 
economic growth and development in these societies.

Applying the Ruttan-Kuznets model (Chapman, 1999) based on the proposal that the demand for environmental quality increases with the level of income as well as the rate of increase in income, to the effect that a positive relationship exists between environmental degradation and income at low income levels, while a negative relationship exists between these at high income levels, we develop an Environmental Quality Trajectory (EQT) model. The EQT depicts environmental quality as a positive function of two environmental parameters, namely, the depletion-stress parameter, and the GDP level, and a negative function of another environmental parameter, namely, the environmental degradation intensity index. As the values of the environmental degradation index (EDI) for any given country can be found and used as an indication of the "environmental health" of the country, the values of these parameters, both cross-sectional and time series, can be determined and used to assess the state of environmental performance for not only the country concerned, but also for other countries. This is the theme of the present study.

Granted that a poverty-stricken developing country would tend to be primarily concerned with ways and means to achieve greater economic growth, such a country is expected to be less concerned with environmental preservation if at all. But this view fails to take into account the fact that ultimately any level of environmental degradation that occurs as a result of economic growth would ostensibly also tend to inhibit the pace of economic growth itself. The pollution-haven hypothesis (Cole, 2004) maintains that developing countries tend to function as pollution havens whereby industrial firms from developed countries could easily relocate their operations without being compelled to comply with stringent environmental standards and regulations that obtain in their home countries. This is premised on two basic suppositions: (1) tough environmental control measures in the developed countries cause firms there to seek relocation in developing countries where such controls are either lax or nonexistent; and (2) many developing countries, in their desperate bids to attract industries from developed countries, have encouraged or even actively invited firms with promises of minimal or outright waiver of any environmental standards.

\section{Environmental Issues in Economic Growth: Some Recent Literature}

Sachs (1997) offered some enlightening quantitative measures of how much shortfalls (in terms of percentage national income growth) countries in certain regions of the world suffer as a result of their peculiar natural and geographical (that is, environmental) factors. Africa, for example, suffers a shortfall in growth due to "poor geography" and natural health hazards of an estimated 2.3 percentage points per year. Among other things, bad climates, poor soils, physical isolation, infectious tropical diseases and the consequent poor human and animal health, are likely to hinder growth despite the type of policy being pursued.

The likely hazardous effect of economic growth on the environment had been examined by Thomas and Belt (1997) in a work that considered the potential impacts of economic growth on environmental quality. They determined that the achievement of high growth and poverty reduction in the Newly Industrialized Countries (NICs) of East Asia and China have been at the expense of severe environmental degradation. Several environmental factors were cited as the evidence of the severe environmental threat that growth has brought to the East Asia region. The study specifically covered the southeast Asian countries of Malaysia, Singapore, Indonesia, and Thailand; and apparently, similar situations have occurred in other Asian countries of Japan, South Korea, Hong Kong, and Taiwan where rapid economic growth and development have taken place during the twentieth century. For example, it was noted that 9 of the world's 15 cities having the highest levels of particulate air pollution are in this region. Also, close to 20 percent of vegetation-covered land in the region suffered from soil degradation through erosion, water-logging, and over-grazing beyond world averages. Furthermore, the region had undergone some of the highest rates of deforestation in the world, and about 50 percent to 75 percent of its coastlines and marine protected areas were classified as areas of highly threatened biodiversity. The study suggested that the challenges of economic growth and the environment needed to be addressed simultaneously as a matter of high priority. Yet these environmental problems are not solely caused by rapid economic growth and development. In fact, they could equally be the results of growing poverty and underdevelopment. Lopez (1994) suggested that the experiences of many countries in Africa, South and Central America, and parts of East Asia indicate that slow-growing or negative-growing economies could equally suffer from severe environmental deterioration brought by the fact of their economic deprivation and underdevelopment. Pressures of over-population and mass poverty cause severe deforestation, overgrazing, and growth of urban slums and squalor in the bid to eke out basic existence (Frankel, 2005).

Stern et al (1996) applied the environmental Kuznets curve (EKC) in which it is assumed that there is no feedback from the quality of the environment to production possibilities, and in which trade has a neutral effect 
on environmental degradation. They found that whether or not further development will reduce environmental degradation is dependent on the assumption that world per capita income is normally distributed (although the reality is more like the median income is far below the mean income). The work carried out simulations combining EKC estimates from the literature with World Bank forecasts for economic growth, for individual countries, aggregating over countries to derive the global impact. The authors concluded that within the horizon of the Bank's projected quarter century forecast (2020), global emissions of $\mathrm{SO}_{2}$ continue to increase. Forest loss stabilizes before the end of the period but tropical deforestation continues at a constant rate throughout the period.

Chapman (1999) presented an analysis applying the theories of Simon Kuznets and Vernon Ruttan in depicting the relationship between environmental degradation and per capita income. The idea of Environmental Kuznets Curve depicting a positive relationship between environmental degradation and income at low income levels, and a negative relationship between these at high income levels, has been applied by some researchers such as Suri and Chapman (1998) and Selden and Song (1994). The Ruttan theory is based on Ruttan's (1971) proposal that the demand for environmental quality increases with the level of income as well as the rate of increase in income. The Kuznets model and the Ruttan model propose separate and opposite relationships between environmental degradation and per capita income. The latter proposed that high levels of environmental degradation are consistent with low per capita income; but as per capita income increases, the level of environmental degradation falls steadily. The nature of causality implied by this proposal is not clearly stated until the Kuznets case is considered - in which case environmental degradation is positively correlated with low levels of per capita income up to a maximum level, and then becomes negatively correlated with per capita income thereafter. The level of per capita income corresponding to the maximum level of environmental degradation can be said to represent an individual's environmental quality income threshold, $\mathrm{y}^{*}$; and some studies based on US data have indicated that $\mathrm{y}^{*}$ would range around US $\$ 4,000$ to US $\$ 5,000$ (Chapman 1999). Thus, for all per capita income levels below $\mathrm{y}^{*}$, a positive causal relationship can be said to exist between per capita income and environmental degradation; and $y^{*}$ can be identified and depicted as the environmental quality income threshold.

A related work by Khanna and Plassmann (2004) argued that the threshold income level at which the Environmental Kuznets Curve turns downwards (or the equilibrium income elasticity of demand for environmental quality changes sign from positive to negative) depends on the ability to spatially separate production and consumption. The authors tested this household demand for "better environmental quality" by estimating the equilibrium income elasticities of five pollutants based on 1990 U.S. data. They found that the change in sign occurs at lower income levels for pollutants for which spatial separation is relatively easy as compared to pollutants for which spatial separation is difficult. The results led them to conclude that high-income households in the U.S. have not yet reached the income level at which their demand for "better environmental quality" is high enough to cause the income-pollution relationship to turn downwards.

Applying the theories that the demand for environmental quality depends on people's income levels, Ezeala-Harrison (2003) proposed that as pollution levels and forest degradation increase as incomes grow (for example, during the phase of economic development when per capita income lies around US\$4,000 to US $\$ 5,000$ ), it would mean that at lower income levels, pollution-stress (p-stress) and depletion-stress (d-stress) on the environment would be greater relative to higher income levels. It is supposed that beyond the environmental quality income threshold, greater demand for environmental quality tends to bring about decreases in the intensities of d-stress and p-stress. Thus, as stated by Chapman (1999), the Ruttan-Kuznets model posit that income levels and living standards are major factors that influence the desire and the demand for greater environmental quality in society. The present study extends these contributions in the Environmental Quality Trajectory model, offering a theoretical and empirical analysis of the role of the environment and how it impacts growth and development for developing countries.

\section{Environmental Constraints on Economic Growth in Poor Countries}

Society's ongoing economic activities of production and consumption exact heavy tolls on the environment. The process of industrialization, agricultural development, housing, physical infrastructure, machinery, mining, forestry, and aviation, all bring about environmental deterioration. For example, industrialization processes bring with them air and water pollution, as well as pollution of the earth surface in areas where industrial solid wastes were disposed. These Negative Environmental Impact (NEI) problems are often taken lightly until their effects begin to manifest through severe negative impacts on human health, production costs, and resource availability. The NEIs of human needs manifest in direct and indirect costs that are imposed, as well as the costs involved in environmental quality controls designed to mitigate these effect (measures such as air and water quality control, 
hazardous waste disposal, solid waste management, and management of toxic substances from industrial production). Some examples are the imposition of emission standards on industries and automobiles, installing water purification facilities, and imposing vigorous conservation measures on natural resources use (such as fish stocks, minerals, and trees); and there is no question that these environmental enhancement measures would likely result in higher short-run production costs in firms and industries within the country. The NEIs on growth and development are measures of the most direct means whereby a country's state of economic performance may be impaired by environmental factors.

Broadly defined, the NEIs include the toxic contamination of the air, atmosphere, the land surface, and the waters. It includes desertification, deforestation, endangered animal species, acid rain, global warming, ozone layer thinning, and solid waste disposal, not to mention the "eye sore" effect of environmental use whereby some members of society are denied their "psychic" benefits from an unspoiled environment. The production (supply side) and consumption (demand side) economic activities of society each have their NEIs encompassing the solid, liquid, and gaseous wastes generated in the course of these economic activities. And the NEIs in turn tend to impair the human economic activities of production and consumption, resulting in lower economic activity. On the supply side the by-products of production affect the need to breathe clean air, have clean and uncontaminated water, nonhazardous living space, and unpolluted food supply. On the demand side the by-products resulting from consumption activities are closely associated with the population level of the country -- waves of rural-urban migration and their attendant explosive growth of urban communities, growth of urban slums with poor living conditions resulting in congestion, squalor, and unsanitary conditions, conditions that often become prone to the spread of diseases and epidemics, all of which are detrimental to economic growth and development.

In many of the poor countries that have significant levels of industrial expansion as well as large-scale applications of chemicals to agricultural production and mining, rivers and lakes have often been used as a means of disposing toxic waste products and heavy metals. These rivers and other groundwater have been largely contaminated by seepage of hazardous materials from industrial sites and solid waste dumps. This presents serious environmental hazards to the society. Poor environmental situations such as pollution would impair human health, and would also impair the productivity of labour. Higher medical costs would often result in higher production costs as firms pay higher health-care expenses to their labor force. The increasing environmental problems of deforestation, global warming, and species extinction are stark realities in many poor countries, where the rapid depletion of forests which act to absorb atmospheric carbon dioxide results in increased concentration of carbon dioxide gas in the atmosphere resulting in atmospheric warming. This greenhouse effect worsens the already unsuitable high temperature problems in many developing countries.

It is important to note that environmental impacts on economic growth and development present themselves very differently to the high-income countries and the low-income countries. For whereas environmental problems are mainly human-made in the former, they are mainly naturally caused in the latter. For example, many poor countries in Asia, Africa, the Middle East, Latin America and the Caribbean tend to confront very significant natural environmental problems as these regions occupy the parts of the globe with very harsh and least favorable environmental conditions. In water pollution, for example, parts of Africa and South Asia suffer from water-borne parasites that infect humans and animals due to pollution from natural sources (such as dirty well-water or ground-water that carries guinea-worms) rather than pollution from industrial waste products. Many of these areas have arid or semi-arid climates, associated with very harsh environmental living conditions. Geographically, the bulk of the areas occupied by the developing countries lie within a span of about 2,500 kilometres on either side of the equator, with their tropical effects extending much wider than this range. Three types of tropical climates are found in these regions. These are: the wet equatorial tropical climate, characterized by high humidity and constant (equatorial) rains of about 190 to 300 centimetres per year; the monsoon tropical climate, characterized by a mix of alternate wet and dry seasons; and the arid tropics, characterized by little or no rainfall. In recent years, the effects of the types of severe drought that are characteristic of these areas have been seen in the world by the famines of Ethiopia (1985 and beyond), Somalia (1993 and beyond), Mozambique, and Sudan, all in Africa. They have also been evident in the Philippines, Bangladesh, and North Korea, in Asia.

The natural environmental constraints in many poor countries tend to impede education and human resource development, agriculture, infrastructural construction, and industrialization. The severe dehydrating effects of the tropical heat is not only restrictive to the application of human mental and physical efforts in production, it also necessitates the constant needs for food and nourishment during the course of every production activity involving labor, thereby tending to not only raise the labor costs of production but also to render labor relatively less productive than capital (resulting in the desire for employers to prefer capital to labor, that is, relative 
unemployment of the labor force). And the tropical environment, with its attendant extreme heat, high humidity, and absence of frost, are conducive to the growth of destructive bacteria, parasites, insects, pests, and several species of tropical diseases that constantly inhibit plant and animal life (Sachs, 1997). Tropical storms are incessant and extremely destructive. The unpredictable torrential rains simply wash away the soil with its ferocious erosions, often sweeping away agricultural crops and leaving behind lands that are largely unsuitable for habitation. Arguably, some potentially fertile areas exist in the tropics. Much has been written of the volcanic soil of the East African highlands and parts of Asia and the Pacific regions, as well as the clay soil of the alluvial plains of Africa and South America. These are all areas of the tropical zones that may be particularly suitable for agricultural development. Other than these, however, the bulk of the soil found in much of the tropics are formed from old acid parent rock, poor in calcium and other plant nutrients. Most parts of West and Central Africa, South Asia, and South America, are rain forest regions. Agricultural land tenure involve the removal of the forest, and as this is done, the proportion of iron and aluminum hydroxides in the soil tends to increase, resulting in the formation of laterite soil which becomes intractably hard and uncultivable (Grossman Krueger, 1995; Sachs, 1997). Agricultural output is therefore always very limited relative to the amount of investment made, a major constraining factor in economic growth and development.

\section{Model of Environmental Quality Trajectory}

Society's economic needs of supply (production of goods and services) and demand (consumption of goods and services) are all heavily reliant upon the environment by either taking away or adding to it in major ways -either by way of the environment's material resources that are taken from it, or by way of its spatial resources into which the by-products of production and consumption are released and deposited. On the supply side, massive production of society's goods and services impose a depletion stress (d-stress) on the environment; and on the demand side, a combination of direct use of environmental resources and the release and deposit of consumption by-products impose a pollution stress (p-stress) on the environment. These stress factors are negative externalities that together amount to a dual-stress factor that human demands impose on the environment. We denote the dual environmental stress $(s)$ as:

$$
s=p+d,
$$

where:

$$
\begin{aligned}
& \mathrm{p}=\mathrm{p} \text {-stress (the pollution effect), and } \\
& \mathrm{d}=\mathrm{d} \text {-stress (depletion effect). }
\end{aligned}
$$

Thus, total environmental stress can be depicted as an index whose value ranges from zero (possible lower limit) to one (possible upper limit):

$$
1 \geq s \geq 0 \text {. }
$$

The lower limit is the case where $s=0$, which would suggest a scenario in which the environment is virtually free from stress -- a case of environmental utopia where humankind can live off the earth without any environmental consequences whatsoever. The upper limit is the case where $s=1$, which implies a case scenario of environmental saturation where the environment has reached its assimilative capacity limit of human exploitation. This scenario would suggest the case of the so-called doomsday in which society has run out of environmental support whereby the environment is unable to further provide both material and spatial resources to support human life on the planet earth.

Society's environmental degradation over time is a function of the intensity of the stress being imposed on the environment; the higher the intensity of stress, the greater the amount of degradation, and vice versa. It is the amount of environmental degradation that gives rise to the level of Negative Environmental Impacts (NEIs), which determines the state of environmental quality of the society. Denoting the intensity of environmental degradation as $D$, and expressing the functional relationship between environmental degradation and environmental stress as:

$$
D=f(s), f^{\prime}(s)>0,
$$

the Ruttan-Kuznets relationship can be formally stated in terms of these environmental parameters, population level, and GDP. Following Ehrlich and Holdren (1970) and Chapman (1999), a relationship linking the size of a society's population, per capita income, and pollution per unit of consumption imposed by that income, may be specified.

Defining the following terms:

$$
\mathrm{D}=\text { Environmental degradation intensity, }
$$




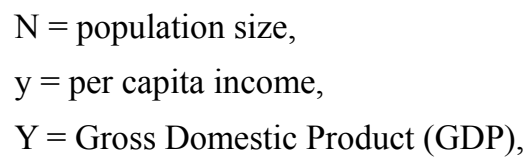

then the society's level of environmental degradation intensity can be written as the product of the size of population, the level of per capita income, and the level of stress intensity per unit of goods and services produced and consumed in the economy:

$$
D=N . y . s=N . y \cdot(p+d)
$$

And given that $y=Y / N$, and substituting, we have

$$
D=Y(p+d)
$$

As equation (2) formalizes the Ruttan-Kuznets theories linking environmental degradation with income, it may be termed the Ruttan-Kuznets equation, which expresses environmental degradation at any given time period as a fraction (proportionate amount represented by the level of stress intensity) of the society's GDP level. A slight difference here though is that this model relates environmental degradation to level of GDP rather than per capita GDP. This difference should not alter the theoretical underpinning that makes this model analogous to the Ruttan-Kuznets theory. Moreover, equation (2) represents an explicit version of the implicit relationship that is equation (1), expressing the total intensity of environmental degradation as a positive function of environmental stress intensity, and GDP.

The level of pollution intensity represented by the parameter $p$ in equation (2) can be expressed as:

$$
p=D / Y-d,
$$

which shows that pollution, while a positive function of environmental degradation, is a negative function of GDP (Ruttan theory) and depletion stress. But our concern is with environmental quality, which is the negative of environmental pollution. The level of environmental quality intensity, $Q$, is deduced from this relationship as:

$$
Q=-p=d-D / Y
$$

Thus environmental quality is given as a positive function of the d-stress parameter and GDP level, and a negative function of environmental degradation intensity.

Equation (3) yields the trajectory of environmental quality over time; the ratio $D / Y$-- the ratio of environmental degradation intensity to GDP -- gives the measure of environmental degradation index (EDI) for any given country. It indicates an index for determining the "environmental health" of a country. Its values, both cross-sectional and time-series, can be determined and used to assess the state of environmental performance across countries or trend performance within a given country (that is, applying known values of GDP, the values of EDI $(D / Y)$ would depend on the value of the environmental degradation intensity $(D)$. This can be proxied by monetary costs of NEIs, such as cost of treating environment-related illnesses (say, air and water pollution ailments), contingent valuation of eye-sore costs, cost of suburban-inner city commuting, and the like.

The upper limit of $Q$ is 1 , at which level it would indicate that for all possible levels of GDP, environmental quality would attain an optimal (maximum) intensity level. However, the ability of a country to attain this optimal trajectory level at the given GDP level and time period is the crucial environmental policy objective facing any country. But a country can be on any EQT time path according to its level of economic development and state of "environmental health". As a country's environmental health improves, it is able to shift its EQT toward the optimal level; but the poorer its environmental health, the more its EQT shifts away from it. The EQT is a steady-state time path of a society's long-run environmental status that can be applied toward long-term planning and projection of the country's environmental targets. For example, a country may project its environmental quality target at some future date and corresponding level of GDP. Under the Kyoto Protocol, various countries undertook to achieve some set levels of reduced emissions (pollution) over a certain time period. In this case a given country would be setting choices for its process of shifting its EQT curves upward while operating along the curve at the given combinations of levels of environmental quality intensity, GDY, and EDI. The country could then determine how fast it wishes to attain these set levels by manipulating its levels of environmental degradation. Under the Kyoto Protocol, various countries committed to a voluntary systematic reduction of their levels of greenhouse-gas emissions, some committing to cutting their greenhouse gasses by as much as 6 percent from their 1990 levels, by the year 2010 .

\section{Empirical Analysis}

Some previous studies have carried out empirical work using cross-country data to verify the relationship 
between per capita income and a selection of environmental parameters. Notable ones among these include Khanna and Plassmann (2004, Jha and Murthy (2003), Grossman and Krueger (1995), Selden and Song (1994), and Shafik (1994). The present study considers a mix of selected low-income countries and looks at their data on a combination of environmental variables based on the EQT equation of the study. A combination of time-series and cross-sectional data are accessed -- time series data for a cross-sectional representation of 5 countries -- to verify their levels of environmental quality and how far they are impacted by the variables of the EQT model. The linear specification of the EQT equation (3), with the level of environmental quality as the dependent variable, is given as:

$$
\mathrm{EQ}=\beta_{0}+\beta_{1} \mathrm{DSTR}+\beta_{2} \mathrm{PSTR}+\beta_{3} \mathrm{EDI}+\beta_{4} \mathrm{GDP}++\beta_{5} \mathrm{PCI}+\mathrm{e}
$$

where

$$
\begin{aligned}
& \mathrm{EQ}=\text { level of environmental quality, } \\
& \beta_{0}=\text { intercept term, } \\
& \text { DSTR = level of environmental depletion stress, } \\
& \text { PSTR = level of environmental pollution stress, } \\
& \text { EDI = environmental degradation index, } \\
& \text { GDP = Gross Domestic Product, } \\
& \text { PCI = per capita income, } \\
& \text { e = error term. }
\end{aligned}
$$

The signs expected for the various explanatory variables of the environmental quality equation helps provide a preliminary indication of the paper's central intuition regarding the impact of the EQT variables DSTR, PSTR, GDP, and PCI (and especially to verify the Ruttan-Kuznets postulates). It is expected that the parameter estimate for:

- DSTR be negative (as more natural resources depletion such as deforestation and crude oil exploitation reduces environmental quality).

- PSTR be negative (higher pollution stress reduces environmental quality).

- EDI be negative (greater environmental degradation results in lower environmental quality).

- GDP be positive (to verify the Ruttan-Kuznets postulates).

- PCI be positive (to verify the Ruttan-Kuznets postulates).

\subsection{The Data Set and Estimation}

The data was collected from a cross-section of World Bank's World Development Report, 1990-2012, and World Resources Institute's EarthTrends Database, 1990-2012. A sample of five developing countries were chosen, namely, Indonesia, Kenya, Mexico, Nigeria, and Zambia -- chosen to ensure representations from the various continental regions and sub-regions of the world. As a result of the vastness of the data set, the sample size covered were quite large. A possible source of weakness in the data is expected because they were time-series data collected and averaged for each country over 22-year periods. Also, it is recognized that there could be possibility of biases in the estimates due to the use of proxies to represent some of the EQT variables. This may raise some question as to how reliable the data would be, and the results need to be taken with caution.

The data set for environmental quality (EQ) is given by the daily measure of the concentration of particulate matter (sulphur dioxide or smog) in the atmosphere of the Capital City area, as measured and reported by the country's Environmental Agency. The DSTR is proxied by the level of yearly expenditures in mining (in the cases of Kenya, Zambia, and Mexico), crude oil exploration (in the case of Nigeria), and forestry (in the case of Indonesia). The PSTR variable is proxied by the yearly expenditures on solid waste disposal reported by the largest municipal area of the country (the capital city area for each of the countries). Each country's GDP (used as the proxy measure of economic activity), and the ratio of the level of smog to the level of economic activity, gives the proxy for EDI of each country. The PCI for each country is sourced directly from the data bank.

The equation is estimated for each country using the 2-stage least squares method, with initial stage involving the equation:

$$
Z_{i}=\alpha_{1} z_{1}+\alpha_{2} z_{2}+\alpha_{3} z_{3}+\alpha_{4} z_{4}+\alpha_{5} z_{5}
$$

where 
$Z_{i}=$ instrument for variables $i=1-5$,

$\mathrm{Z}_{1}=$ population growth rate $=$ instrument for DSTR,

$\mathrm{z}_{2}=$ industrial sector growth rate $=$ instrument for PSTR,

$\mathrm{z}_{3}=\mathrm{GDP}$ growth rate $=$ instrument for EDI,

$\mathrm{Z}_{4}=$ annual government expenditure $=$ instrument for GDP,

$\mathrm{z}_{5}=\mathrm{GDP}=$ instrument for PCI.

\subsection{The Results}

Table 1 provides the descriptive statistics of the data for each country used in the estimation, showing the sample summary and the quantitative features of each variable. Table 2 gives a tabulation of the regression results. Examining the t-statistics, there is an indication of some generally robust degree of statistical significance for the majority of the estimated coefficients. The values of the $F$-ratios are mixed in terms of the overall confirmation of the fit; the F-values in the cases of Indonesia, Mexico, and Zambia indicate strong fitness while the cases of Kenya and Nigeria show relative weakness in the fit. Also, the values of the $R^{2}$ show some variations across the various countries, with some being quite low, like in the cases of Kenya, Mexico, and Nigeria; and it is supposed that these could be due to the use of the cross-sectional data involved. Nevertheless, despite the relatively high F-ratios, a pairwise correlations test of the presence of multicollinearity is performed among the independent variables (especially EDI, GDP, and PCI) to ascertain the reliability of their estimated coefficients. A mild correlation coefficient (0.502) is found among them, suggesting that some caution should be observed in interpreting the values of the estimated coefficients in the regression.

Table 1. Descriptive statistics of EQT data (sample means) for selected developing countries

\begin{tabular}{llllll}
\hline & Indonesia & Kenya & Mexico & Nigeria & Zambia \\
\hline EQ & 0.821 & 0.286 & 0.688 & 0.209 & 0.183 \\
& $(0.16)$ & $(0.29)$ & $(0.35)$ & $(0.18)$ & $(0.22)$ \\
DSTR** & 39.2 & 4.1 & 18.3 & 33.6 & 1.62 \\
& $(2.45)$ & $(3.16)$ & $(2.84)$ & $(4.2)$ & $(2.1)$ \\
PSTR* & 2.6 & 3.7 & 4.5 & 1.9 & 2.2 \\
& $(3.54)$ & $(1.86)$ & $(2.02)$ & $(1.82)$ & $(2.52)$ \\
EDI & 0.79 & 0.39 & 0.56 & 0.31 & 0.33 \\
& $(0.19)$ & $(0.26)$ & $(0.11)$ & $(0.17)$ & $(0.14)$ \\
GDP** & 894.9 & 51.2 & 1287 & 498 & 23.8 \\
& $(5.24)$ & $(11.05)$ & $(6.38)$ & $(4.92)$ & $(7.41)$ \\
PCI & 3551 & 933 & 9818 & 2742 & 1563 \\
& $(3.9)$ & $(2.86)$ & $(5.41)$ & $(4.06)$ & $(3.12)$ \\
$\mathrm{N}$ & 22 & 22 & 22 & 22 & 22 \\
\hline
\end{tabular}

Key: Standard Deviations in parenthesis; $\mathrm{N}=22 ; *$ \$million; ** \$billion 
Table 2. Regression estimates of EQT variables for selected developing countries

\begin{tabular}{llllll}
\hline & Indonesia & Kenya & Mexico & Nigeria & Zambia \\
\hline DSTR & $4.1^{*}$ & $3.4^{* *}$ & $2.8^{*}$ & $5.2^{*}$ & $3.8^{* *}$ \\
& $(1.67)$ & $(2.86)$ & $(1.71)$ & $(1.79)$ & $(3.8)$ \\
PSTR & $3.84^{* *}$ & 0.92 & $2.06^{* *}$ & $1.24^{*}$ & $1.13^{* *}$ \\
& $(2.91)$ & $(1.02)$ & $(3.22)$ & $(1.86)$ & $(2.08)$ \\
EDI & 0.33 & 0.32 & 0.34 & 0.30 & 0.29 \\
& $(0.19)$ & $(0.26)$ & $(0.11)$ & $(0.17)$ & $(0.14)$ \\
GDP & $2.3^{*}$ & $1.9^{* *}$ & $-4.3^{* *}$ & $-2.4^{* *}$ & $3.1^{* *}$ \\
& $(1.72)$ & $(3.91)$ & $(4.21)$ & $(3.43)$ & $(2.99)$ \\
PCI & $2.18^{* *}$ & $1.66^{*}$ & $-2.08^{*}$ & $-1.87^{*}$ & $1.61^{*}$ \\
& $(4.21)$ & $(1.82)$ & $(1.69)$ & $(1.78)$ & $(1.81)$ \\
R2 & 0.69 & 0.48 & 0.42 & 0.51 & 0.62 \\
F. & 14.3 & 6.2 & 19.1 & 9.5 & 23.4 \\
d.f. & 17 & 17 & 17 & 17 & 17 \\
$\mathrm{~N}$ & 22 & 22 & 22 & 22 & 22 \\
\hline
\end{tabular}

Key: t-statistics in parenthesis

** Significant at the $5 \%$ level

* Significant at the $10 \%$ level

The most intriguing results seem to be the mixtures in the signs of the coefficient estimates of the GDP and PCI variables, namely, the negative coefficient estimates of the GDP and PCI variables for Mexico and Nigeria, and positive estimates of these variables for Indonesia, Zambia, and Kenya. The magnitudes of these estimates are sizable for GDP (averaging to about 2.8) and moderate for PCI (averaging to about 1.88), despite their variations in signs. The coefficient estimates of the GDP (all significant at the 5 percent level, except for Indonesia for which it is significant at the 10 percent level) reveal that in all the countries (especially Mexico and Zambia to a significant extent as indicted by the magnitude of the estimates, and Nigeria and Indonesia to a relatively lesser extent), economic growth is consistent with enhanced environmental quality. This is supported by the results of the estimated coefficients of the PCI variable for these countries as well (especially for Indonesia and Mexico). However, negative coefficients of these income variables for Mexico and Nigeria (all significant at the 5 percent level for GDP and significant at the 10 percent level for PCI, for both countries) appear to be indicating something quite different. The results suggest that environmental quality is diminished by economic growth in these two countries. One can only infer that most probably the differences in outcome among these cohorts of developing countries could be attributable to sociocultural and political differences among them.

The estimated coefficient estimates of the environmental depletion-stress index (DSTR) reveal a relatively large impact for resource depletion (averaging about 3.9) and significant at the 5 percent level for Kenya and Zambia, and at the 10 percent level for the Mexico, Indonesia, and Nigeria). Clearly, these results appear to be in line with the reported problems of deforestation and mine devastation in the Eastern African and South Asian regions, as well as the oil-well devastation of the environment in Southern Nigeria. For the pollution-stress variable (PSTR), the magnitudes of the coefficient estimates average out from highs of 3.84 for Indonesia and 2.06 for Mexico, to lows of 0.92 for Kenya, 1.13 for Zambia and 1.24 for Nigeria; and significant at the 5 percent level for all except Nigeria at the 10 percent level and Kenya for which it is not statistically significant. Thus as expected, the results indicate that pollution stress is very important in determining environmental quality.

In the main, the results underlie some very important issues concerning the environment and the major factors that shape its role in economic growth and development in low-income countries. And most importantly, and in particular, while the results appear to generally lend support to aspects of the Ruttan-Kuznets propositions (Zambia, Kenya, and Indonesia), it seems to refute some aspects of it (Mexico and Nigeria). The significance of 
this finding is that they point vividly to the realization that the implications of the environmental Kuznets curve does not seem to hold equally to all low-income countries.

\section{Policy Conclusions}

The findings of this study yield some growth-oriented environmental policies for developing countries that need to be adopted to pursue corrective measures to address the inevitable violation of the environment's sustainable development imminent in the course of economic activities. The policy direction is the need for a developing country to seek to achieve and sustain a steady long-term economic growth and development path, together with environmental sustainability along an environmental quality trajectory such as the model provided in this study. With an effective sustainable development policy program, a developing country could even operate along its optimal trajectory path consistent with a strong long-term drive for economic growth, for a developing country which is among the least able to afford the disruptive and distortionary effects that environmental degradation entails on economic growth. The question then is what specific policy actions need to be implemented in the developing country to enable it achieve and operate along such an optimal environmental quality trajectory.

Being relatively less developed (or even undeveloped), environmental problems would be more detrimental to economic growth and development in the developing countries than the developed countries. Developing countries tend to be relatively more dependent on agriculture, and natural resources, and extractive industries, and therefore more vulnerable to climatic changes. Moreover, the implication of being a pollution-haven is that the country's environment suffers permanent damages that could limit the potentials for economic growth.

Apart from the pollution side of the environmental problem in developing countries, there is also the more serious aspect relating to unsuitable environmental conditions that these countries inhabit. This presents the most challenging environmental constraint to economic growth. To help mitigate the impacts of this condition, of central importance there is the need to encourage the choice of rural dwelling among the population through aggressive programs of rural and agricultural development. These programs are to be combined with programs of education, urban planning, and infrastructural construction. With the improved level of development that these measures would give, notably, increases in the per capita income, the country is able to attain higher EQT levels.

High poverty levels in developing countries lie behind the high levels of environmental degradation. Conservation and sustainability measures would have little importance in a society lacking basic needs of food and housing. Increasing economic well-being contributes an important solution to environmental degradation; for, as people get better off economically, there is a reduced tendency for slum-living, over-grazing, or pollution tolerance. But it appears people are not getting better off in the developing countries. Thus, the forests continue to be depleted by slash-and-burn farming methods, and trees are depleted by loggers who ignore environmental costs as they pursue their immediate means of sustenance.

Environmental protection need not be sacrificed for the convenience of short-term growth. This is to say that the so-called policy of grow first and clean up later that many developing countries seem to choose in their bids for quick achievement of growth, would prove to be a very costly and unwise strategy, both economically, socially, and ecologically. A high level of environmental degradation brings immediate economic and social costs that impair the economy's short-term growth performance. Health problems, asset and property depreciation, and high production costs are only few of the most obvious negative externalities. The long-term problems of resource depletion and atmospheric alteration add to the overall high cost of the grow-first and clean-up-later policy that make it an unwise policy.

As for the pollution-havens, it should be noted that both the polluter and the polluted countries are ultimately hurt by this policy. The environment is a global public good whose potential benefits and costs ultimately extend to all societies irrespective of jurisdiction. For example, rain forests in developing countries support much of the world's species which possess overwhelming ecological, biological, and medicinal values. Rain forests also act as carbon sinks -- as they contain new and growing plants that absorb carbon from the atmosphere -- thereby reducing atmospheric warming. Creating pollution havens reduces these potentials and denies both the polluting and polluted countries those environmental benefits.

Because the environment is a global public good, the world as a whole has an important stake in environmental preservation efforts in developing countries. This is more so because of the constraints which growing poverty levels place on the abilities of the developing countries to attain optimal environmental trajectories themselves. This calls for policy responses on the part of the rich countries designed to help developing countries attain their optimal EQT levels. Rather than exploiting them as pollution havens, the rich countries need to provide assistance in the form of compensational support to developing countries to help them defray the opportunity costs of environmental preservation. And this effort should go beyond mere allocations of foreign aid as 
commonly practiced.

\section{References}

Abler, D. G. (1993). NAFTA, Agriculture, and the Environment in Mexico. American Journal of Environmental Economics, 75. http://dx.doi.org/10.2307/1243594

Agaras, J., \& Chapman, D. (1999). A Dynamic Approach to Environmental Kuznets Curve Hypothesis. Ecological Economics, 28, 267-277. http://dx.doi.org/10.1016/S0921-8009(98)00040-8

Alpay, S. (2001). Measuring the Impact of Economic Growth and Trade Liberalization on Environmental Policy Performance: Comparison of Developed and Developing Countries. Paper presented at the 35th Annual Meeting of the Canadian Economics Association, Montreal, June.

Chapman, D. (1999). Environmental Economics: Theory, Application and Policy. Don Mills,Ontario: Addison Wesley, pp. 28-31.

Cole, M. A. (2004). Trade, the Pollution Have Hypothesis and the Environmental Kuznets Curve: Examining the Linkages. Ecological Economics, 48(1), 71-81. http://dx.doi.org/10.1016/j.ecolecon.2003.09.007

Cropper, M., \& Griffith, C. (1994). The Interaction of Population Growth and Environmental Quality. American Economic Review Papers and Proceedings, 84, 250-254.

Eskeland, G. S., \& Harrison, A. E. (2003). Moving to Greener Pastures: Multinationals and the Pollution Haven $\begin{array}{lllll}\text { Hypothesis. Journal of Development } & \text { Economics, } & 70(10), & 1-23 .\end{array}$ http://dx.doi.org/10.1016/S0304-3878(02)00084-6

Ezeala-Harrison, F. (2003). Environmental Issues in Economic Growth: Application of an EQT Model for Developing Countries. In J. Baffoe-Bonnie, \& M. Khayum (Eds.), Contemporaty Economics Issues in Developing Countries. Westport, CT.: Praeger Publishers.

Ezeala-Harrison, F. (2006). Can EQIP Enhance Environmental Quality: A Time-Series and Cross Sectional Analysis. Southwestern Economic Review, 331(10), 137-147.

Frankel Jeffrey, A. (2005). Is Trade Good or Bad for the Environment: Sorting out the Causality. Review of Economics and Statistics, 87(1), 85-91. http://dx.doi.org/10.1162/0034653053327577

Grossman, G. M., \& Krueger, A. B. (1995). Economic Growth and the Environment. Quarterly Journal of Economics, 110, 353-377. http://dx.doi.org/10.2307/2118443

Jha, R., \& Murthy, K.V. B. (2003). An Inverse Global Environmental Kuznets Curve. Working paper Series, (11-2), Australian National University. http://dx.doi.org/10.1016/S0147-5967(03)00042-8

Kahn, M. E. (1998). A Household Level Environmental Kuznets Curve. Economics Letters, 59, 269-273. http://dx.doi.org/10.1016/S0165-1765(98)00035-4

Kaufman, R. K. et al. (1998). The Determinants of Environmental $\mathrm{SO}_{2}$ Concentrations: Reconsidering the

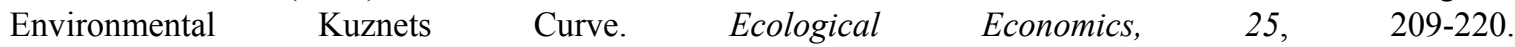
http://dx.doi.org/10.1016/S0921-8009(97)00181-X

Khalafalla, K. (2001). Trade, Economic Growth and the Environment: A Survey. Paper Presented at the $35^{\text {th }}$ Annual Meetings of the Canadian Economics Association, Montreal, June.

Khanna, N., \& Plassmann, F. (2004). The Demand for Environmental Quality and the Environmental Kuznets $\begin{array}{llll}\text { Curve Hypothesis. } & \text { Ecological 225-237. }\end{array}$ http://dx.doi.org/10.1016/j.ecolecon.2004.06.005

Levinson, A., \& Taylor, M. S. (2008). Unmasking the Pollution Haven Effect. International Economic Review, 49(1), 223-254. http://dx.doi.org/10.1111/j.1468-2354.2008.00478.x

Lopez, R. (1994). The Environment as a Factor of Production: The Effects of Economic Growth and Trade Liberalization. Journal of Environmental Economics and Management, 27(2), 163-184. http://dx.doi.org/10.1006/jeem.1994.1032

Panayotou, T. (1997). Demystifying the Environmental Kuznets Curve: Turning a Black Box into Policy Tool. Environment and Development Economics, 4(2), 465-482. http://dx.doi.org/10.1017/S1355770X97000259

Robert, J. T., \& Grimes, P. E. (1997). Carbon Intensity and Economic Growth 1962-1991: A Brief Explanation of the Environmental Kuznets Curve. World Development, 25, 191-198. http://dx.doi.org/10.1016/S0305-750X(96)00104-0 
Ruttan, V. W. (1971). Technology and the Environment. American Journal of Agricultural Economics, 53(5), 707-717. http://dx.doi.org/10.2307/1238069

Sachs, J. (1997, June 14). Nature, Nurture, and Growth. The Economist.

Selden, T. M., \& Song, D. (1994). Environmental Quality and Development: Is the a Kuznets Curve for Air Emissions. Journal of Environmental Economics and Management, 27(2), 147-162. http://dx.doi.org/10.1006/jeem.1994.1031

Shafik, N. (1994). Economic Development and Environmental Quality: An Econometric Analysis. Oxford Economic Papers, 46, 757-773.

Stern, D., Common, M. S., \& Barbier, E. B. (1996). Economic Growth and Environmental Degradation: The Environmental Kuznets Curve and Sustainable Development. World Development, 24(7), 1151-1160. http://dx.doi.org/10.1016/0305-750X(96)00032-0

Suri, V., \& Chapman, D. (1998). Economic Growth, Trade and Energy: Implications for Environmental Kuznets Curve. Ecological Economics, 25(2), 195-208. http://dx.doi.org/10.1016/S0921-8009(97)00180-8

Thomas, V., \& Belt, T. (1997). Growth and the Environment: Allies or Foes. Finance and Development, 34(2), 22-24.

Torras, M., \& Boyce, J. (1998). Income, Inequality, and Pollution: A Reassesment of Environmental Kuznets Curve. Ecological Economics, 25, 147-160. http://dx.doi.org/10.1016/S0921-8009(97)00177-8

World Bank. (1990-2012). World Development Report: Development and the Environment. New York: Oxford University Press.

World Resources Institute. (1990-2012). World Resources. New York: Oxford University Press.

\section{Copyrights}

Copyright for this article is retained by the author(s), with first publication rights granted to the journal.

This is an open-access article distributed under the terms and conditions of the Creative Commons Attribution license (http://creativecommons.org/licenses/by/3.0/). 